\title{
THE FIXATION OF ATMOSPHERIC NITROGEN BY THE SILENT ELECTRIC DISCHARGE PROCESS-I
}

\author{
BY C. FRANCIS HARDING \\ Head, School of Electrical Engineering, Purdue University
}

AND

K. B. MCEACHRON

Research Assistant, Engineering Experiment Station, Purdue University

$7 \mathrm{HE}$ very great increase in the demand for nitrates during the war for the manufacture of explosives and fertilizers, together with the shortage of imported Chile saltpeter, which was the principal source of nitrates before the war, has been emphasized sufficiently in previous papers. This condition of increased demand and curtailed supply led not only to the establishment of many manufacturing plants for the production of nitrates by well-known methods, but also to laboratory research and commercial development in connection with promising new processes.

Such a process, for obtaining nitric acid from the air by means of the silent electric or corona discharge at high voltage, has been investigated throughout a period of several years at Purdue University under the auspices of the Engineering Experiment Station of that institution. Improvements in the yield, resulting from a given input of electrical energy, are being made quite frequently as the investigation progresses and many of the peculiarities of both electrical and chemical reactions of the oxides of nitrogen, combined with ozone, are being disclosed as phenomena incidental to the process under consideration. It has, nevertheless, been snsidered advisable to present, as a progress report, the results obtained thus far in order that, in the spirit of co-operative research, discussions and suggestions of value will result which in turn will hasten the development of the process. With 
this object in view, the results of the investigation being carried on at Purdue University are presented in this paper.

It is well to point out at first the distinction between the process herein described and the arc method of nitrogen fixation. In the former, air is passed through an electro-static field of such intensity that marked corona and some static sparks are produced, but no power arc is established and the temperature is increased but slightly above that of the incoming air. While the arc process of nitrogen fixation is dependent principally upon the very high temperature of the power arc, the silent discharge reaction is the result of electrical ionization of the air at a relatively low temperature.

The fact that electro-static brush discharges and sparks will produce, in a confined volume of air, various oxides of nitrogen and ozone, has been known for many years. Oxidation of these lower oxides of nitrogen by an excess of ozone results in nitrogen pentoxide, $\mathrm{N}_{2} \mathrm{O}_{5}$. This gas, when absorbed in water, produces nitric acid from which the desired nitrates may readily be formed.

\section{EARLIER INVESTIGATIONS}

The investigation, to which this paper forms an introduction, was the result of the translation from the German, by Messrs. G. N. Unger, G. W. Payne and F. S. Weimer, of an article entitled, "The Formation of Nitric Oxides by the Silent Electric Discharge in a Siemen's Tube." The latter was submitted by Hugo Spiel for a doctor's degree at The Technical High School, Vienna, in 1909. Spiel gives credit for the first publication of the effect of this silent electric discharge upon air as follows:

The first observations of the silent electric discharge in literature appeared about 1870, following the work of Andrew, Hauzau, Jean, Thenard and Boillit, with ozone and nitric acid. It concerned the decomposition of carbonic acid and turned the general interest to the chemical effect of the electric discharge in gases. In 1873 the French physicist, Moncel, published a work entitled, "Concerning the Condensed Discharge of the Induction Coil," in which he claimed to have discovered $t^{\text {he }}$ above phenomena in 1853. 
Following a review of the previous work done by others upon the problem, Spiel described a series of laboratory research investigations performed by him upon fixed volumes of air and various artificial nitrogenoxygen mixtures. Spiel's apparatus consisted of a small glass or quartz Siemen's tube, using acidified water electrodes upon either side of an annular air space of only $3 \mathrm{~mm}$. thickness. The electro-static discharge, within this space, was produced by an induction coil and condenser having a sparking distance of $40 \mathrm{~cm}$., and a frequency of approximately 40 cycles per second.

As a result of the exposure of a confined volume of air to the electro-static discharge, at different pressures and voltages, Spiel noted during a single test; first, a decrease in pressure and later, at the minimum pressure, a reversal of the reaction. This reversal was indicated by the presence of brown fumes of $\mathrm{N} \mathrm{O}_{2}$. If the electric discharge was continued beyond this point, the pressure increased to the initial, or to a greater pressure, when equilibrium was established.

The conclusions reached by Spiel have been summarized in the appendix of this paper, because of the bearing they have upon this investigation and the inaccessibility of the original article.

\section{EARLy INVESTIGations AT PURDUE UNIVERsity}

In planning a further investigation of this process, ${ }^{1}$ it was decided that although the work must necessarily be performed with laboratory apparatus upon a comparatively small scale, when contrasted with commercial arc plants, the equipment should be designed and constructed in such a way as to provide for a continuous flow of air through the electric field. There is no reason apparent, therefore, to prevent the construction and continuous operation of a commercial plant based upon the same principle.

To produce the so-called "silent electric discharge" in a column of air, it is, of course, necessary to apply

1. Thesis entitled "The Fixation of Atmospheric Nitrogen by the Silent Electric Discharge at High Voltage," 1917 by G.W. Payne, G. N. Unger and F. S. Weimer. 
an electric potential between conducting plates or concentric pipes, Fig. 1, sufficient in magnitude to exceed the dielectric strength of air under the particular pressure at which such air is being forced through the apparatus, $i$. e., the potential gradient must be such that the molecules of the air are torn apart into ions and neutral atoms which may reunite in new combinations. Such ionized air is a comparatively good conductor of electricity and unless special precautions are taken in the design of the tube, a power arc will result at one point and the potential will be lowered at other points in the field, thus eliminating the reaction.

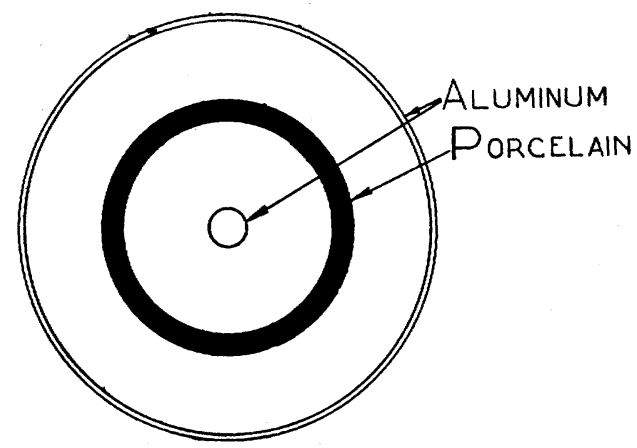

Fig. 1-Elevation of Corona Chamber

Original Apparatus. The apparatus used in this first investigation is illustrated in Fig. 2. Following the passage of the air from the compressor on the left through air chamber, meter and drying apparatus in sequence, it passes into the discharge tube. This consists of a vertical aluminum tube 37.8 in. $(96 \mathrm{~cm}$.) in length and 2.91 in. $(7.4 \mathrm{~cm}$.) internal diameter, inside of which was mounted concentrically a glass tube of slightly greater length, 2.5 in. $(6.35 \mathrm{~cm}$.) diameter and 0.125 in. $(0.318 \mathrm{~cm}$.) thickness. This glass tube provides the barrier of higher dielectric strength than air to prevent the arc from forming. The potential is applied between a coaxial aluminum rod of $0.625 \mathrm{in} .(1.59 \mathrm{~cm}$.) diameter and the outer aluminum tube. The air passes upward between the glass and aluminum tube, and thence the gases pass 
downward between the central rod and the glass tube, emerging from the bottom into the mixing chamber. Receptacles are provided at the right with glass beads and distilled water or a solution of $N / 10$ potassium hydroxide $(\mathrm{KOH})$ for the fine subdivision and absorption of the gases. Traps are placed upon either side of the drying bottles to prevent the sulphuric acid, $\left(\mathrm{H}_{2} \mathrm{SO}_{4}\right)$ which is used as the drying agent,

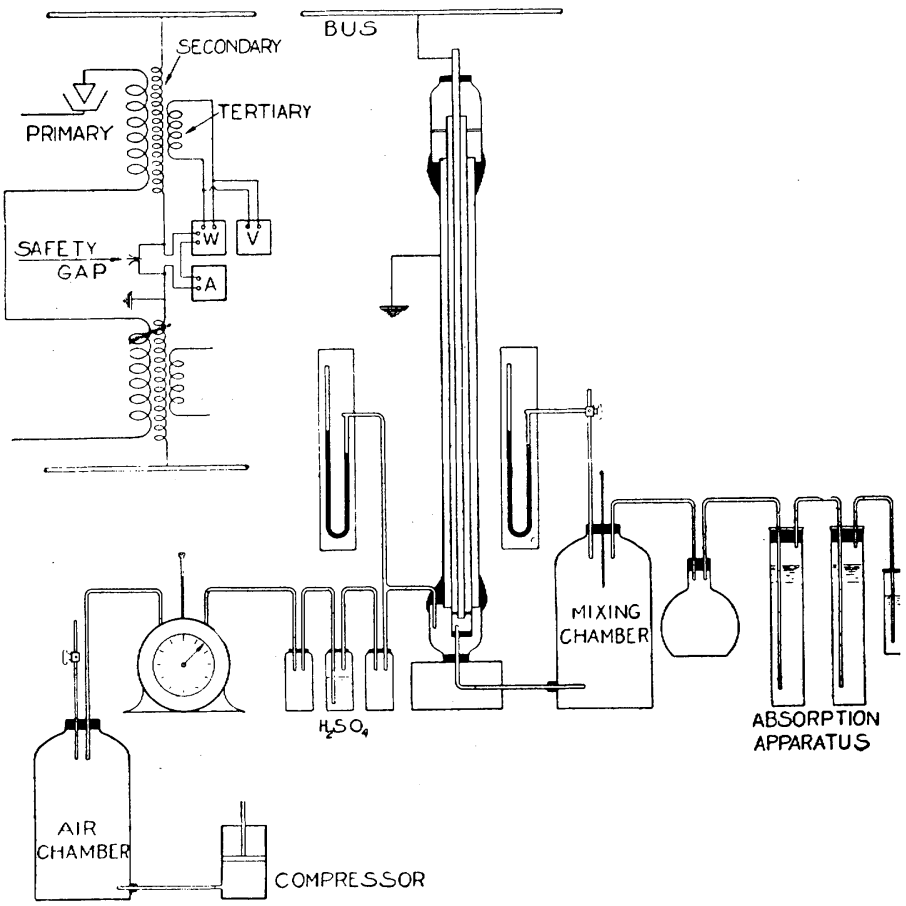

Fig. 2-Original Apparatus

from being carried into the meter or discharge tube. A similar trap is located between the mixing chamber and absorption apparatus to prevent the absorption water from being forced back into the mixing chamber. Manometers and thermometers are installed, as indicated in the figure, for the purpose of determining pressures and temperatures of entering air and effluent gases, respectively.

Power Measurement. A potential in the neighbor- 
hood of 30 kilovolts, alternating at a frequency of 60 cycles, was furnished by a 200-kilovolt, 50-kv-a., air-cooled transformer. The tertiary coil of this transformer, whose potential was calibrated against the A. I. E. E. standard sphere gap in the secondary circuit, provided a convenient means of reading voltage. The potential terminals of the wattmeter were also connected to the tertiary coil. An ammeter and the current coil of a wattmeter were connected, as indicated in the figure, between the neutral point of the transformer winding and ground. Only one side of the transformer was used to supply the potential to the discharge tube. Protective film cut-outs, connected around the meters, prevented accident in case the ground wires of the meters or tube should become disconnected. A Rowland dynamometer, calibrated over a wide range of power factor as a wattmeter, was used in these early tests for measuring the power input to the discharge tube. The difference between the readings of this dynamometer, with and without the tube connection, provided a measure of the net power supplied to the tube, quite apart from any transformer or corona losses on connecting bus bars. This method of power measurement is the same as that used in determining corona loss on transmission lines previously reported to the Institute. ${ }^{2}$

With the methods of gas absorption and power measurement outlined, it was a comparatively simple matter to titrate the nitric acid formed or determine the amount of alkali neutralized thereby per $\mathrm{kw}-\mathrm{hr}$. of energy expended.

Conclusions of Original Investigation. The results of three (3) tests by Messrs. Unger, Payne, and Weimer are listed in Table I.

A study of Table I indicates that thus far the yield by the silent discharge method is very much smaller than those of the arc processes. Some of the conclusions derived from the investigation as indicated seemed however, to warrant further research along similar lines.

2. "Corona Losses between Wires at High Voltages," C. Francis Harding, Transactions A. I. E. E. Vol. XXXI (1912), page 1035. 
1. The reaction is not necessarily a thermal one, but nitrogen pentoxide $\left(\mathrm{N}_{2} \mathrm{O}_{5}\right)$ is formed at low temperatures by the action of the corona at high voltages.

2. Although this reaction is accompanied by much free ozone $\left(\mathrm{O}_{3}\right)$, the lower oxides of nitrogen, so objectionable in the arc process, are apparently not present to any great extent, except in case of reversal of the reaction.

3. Since the effluent gases consist principally of a mixture of nitrogen pentoxide $\left(\mathrm{N}_{2} \mathrm{O}_{5}\right)$, ozone $\left(\mathrm{O}_{3}\right)$ and air, the absorption is more readily accomplished than with the arc process.

TABLE I.

NITRIC ACID YIELDS.

\begin{tabular}{r|c}
\hline Test & $\begin{array}{c}\text { Grams HNO } \\
\text { per kw-hr. }\end{array}$ \\
\hline No. 1 & 4.17 \\
2 & 2.55 \\
3 & 5.55 \\
\hline
\end{tabular}

4. The gases emerge at comparatively low temperatures. Little energy is therefore carried away in the form of heat and no apparatus is needed to make efficient use of this heat energy.

5. The process is a continuous one and, as such, is more adaptable to commercialization than previous investigations of the silent discharge process which have been limited to a single confined volume of air.

\section{IMPROVED APPARATUS}

Encouraged by the possibilities of this process, in spite of the relatively low yields available thus far, the work was taken over upon a larger scale by the Engineering Experiment Station with the assistance of Messrs. H. W. Asire, S. S. Green and H. C. Thuerk. ${ }^{3}$

Apparatus operating upon the same principle, but much larger and more commercial in design, was constructed as indicated in Fig. 3.

3. Thesis entitled "The Fixation of Atmospheric Nitrogen by the Silent Electric Discharge Method," 1918 by H. C. Thuerk and S. S. Green. 
The corona discharge takes place inside an aluminum tube five feet $(1.52 \mathrm{~m}$.) long and six inches $(15.2 \mathrm{~cm}$.) in diameter, mounted in a vertical position, the lower end being about 18 inches $(45.7 \mathrm{~cm}$.) from the floor. A 5/8-inch (1.59-cm.) aluminum rod is placed on the axis of the tube and extends 18 inches $(45.7 \mathrm{~cm}$.)

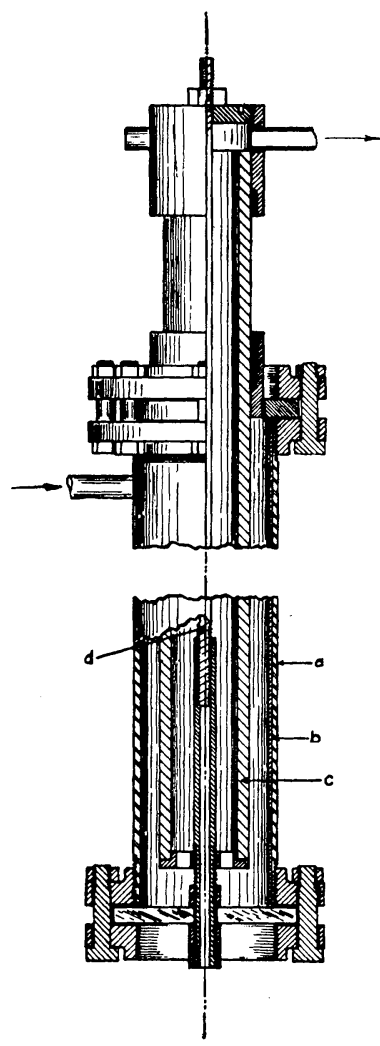

Fig. 3-Discharge Tube

a.-Wrought iron casing.

b.-Aluminum lining.
c.-Porcelain dielectric.

d.-Aluminum electrode.

above the end of the tube. The lower end of the rod is screwed into the end of a $1 / 2$-inch $(1.27-\mathrm{cm}$.) bakelite tube 15 inches $(38.1 \mathrm{~cm}$.) in length. A perforated bakelite disk, about four inches $(10.2 \mathrm{~cm}$.) in diameter, is arranged so that it may be screwed onto the outside of the bakelite tube. This disk furnishes the support for a glazed porcelain tube of three inches $(7.62 \mathrm{~cm}$.) 
inside diameter and $1 / 2$ inch $(1.27 \mathrm{~cm}$.) thickness, the upper end of which projects beyond the end of the aluminum tube, but not as high as the aluminum rod. The top of the tube is closed with a bakelite cap placed over the end of the porcelain tube. A collar, also of bakelite, is inserted between the aluminum and the porcelain tubes. The joints between the porcelain and the bakelite are sealed with a rosin, beeswax and sealing wax compound, which is not appreciably affected by the gases. The bottom of the tube is sealed with a piece of thick plate glass, through the middle of which the bakelite tube is passed. By the use of a mirror, placed on the floor at the proper angle, a view of the inside of the tube is afforded.

Surrounding the aluminum tube is a length of wrought iron pipe, having flanges screwed on either end in such a way that the bakelite collar at the top and the plate glass at the bottom may be clamped securely.

In order that the temperature of the tube may be raised at will, a heating element, consisting of several hundred feet of iron wire, is provided. The heating element, wrought iron pipe and flanges are covered with a magnesia covering which decreases the radiation.

Air enters the tube near the top, and passes downward between the aluminum and porcelain tubes, through the holes in the bakelite disk and up through the inside of the porcelain tube, exhausting through a bakelite tube screwed into the cap over the end of the porcelain. The path of the air is shown in Fig. 4.

A mercury manometer, connected to the inlet pipe, indicates the relative pressure in the discharge tube. The temperatures of the incoming and outgoing gases are measured by alcohol thermometers whose bulbs are in actual contact with the gases. Mercury thermometers were not used on account of the breaking up of the mercury column due to the static charges formed. The mercury is also a conductor which is, of course, a serious disadvantage, and makes their use unsatisfactory.

The aluminum rod is connected to the high-tension transformer, while the outer iron casing is grounded, 
With from 50 to $60 \mathrm{kv}$. impressed on the discharge tube, the space both inside and outside of the porcelain tube may be filled with corona discharge.

Absorption Apparatus. The absorption apparatus consists of an absorbing chamber, separator and precipitator. This apparatus will be more easily understood by reference to Fig. 5 .
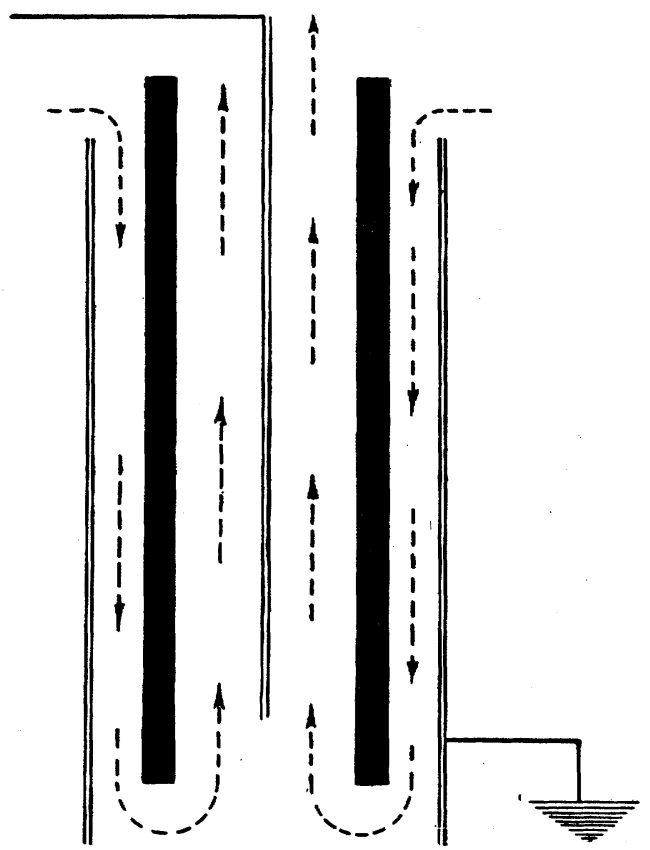

Fig. 4-Path of Air in Discharge Tube

The gases, leaving the discharge tube, bubble through a solution of sodium hydroxide $(\mathrm{NaOH})$ of known strength, contained in the absorption chamber. The bubbles of gas are made to come into contact with quite a large wetted surface as the chamber is partially filled with very short lengths of small glass tubing. The use of the tubing makes possible relatively high air velocities with but little back pressure. The absorbing liquid is titrated both before and after the run, in order to ascertain the amount of $\mathrm{HNO}_{3}$ absorbed. 


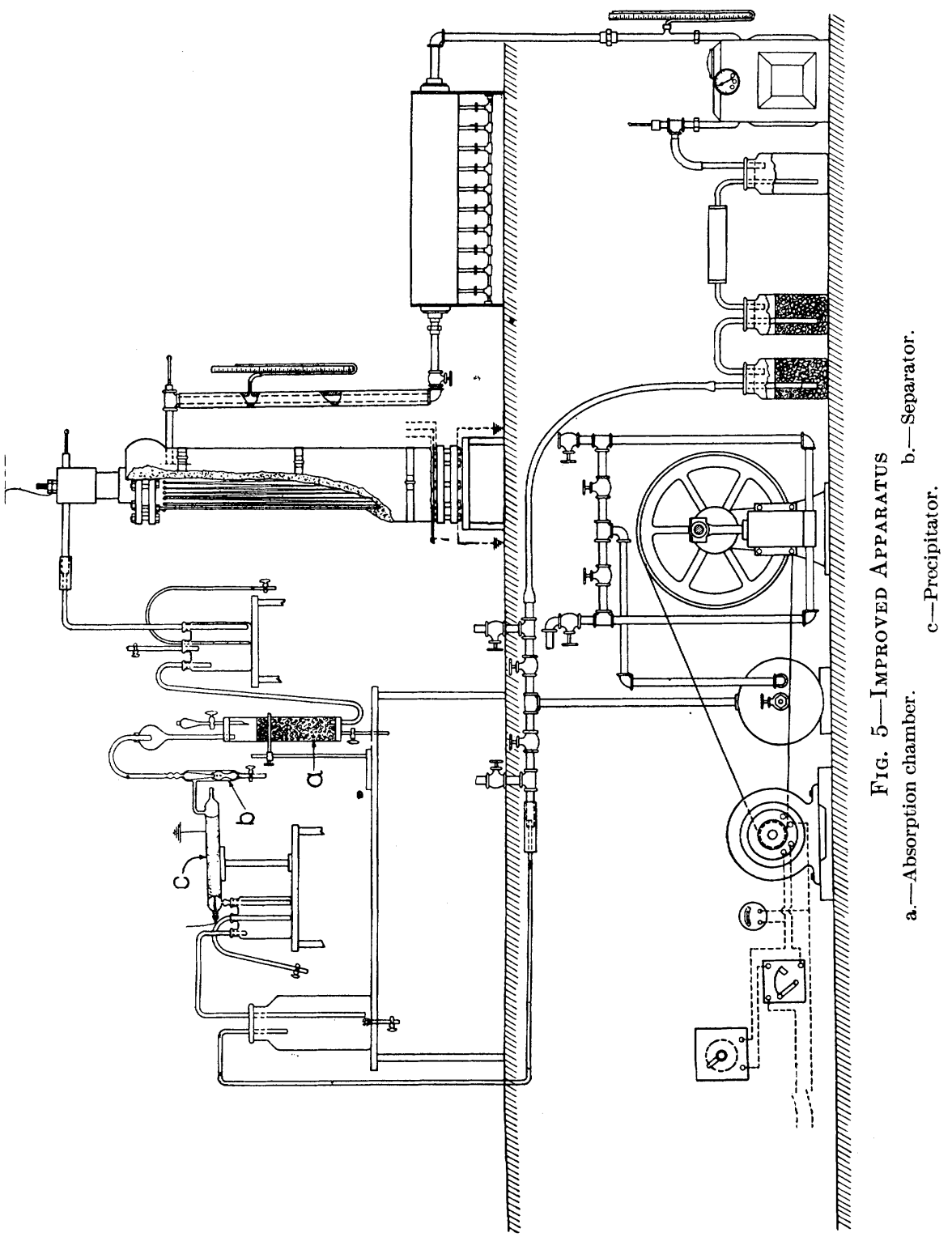


At certain air velocities, a fog is formed over the absorbing liquid and, in order to recover the acid carried with it, a separator, Fig. 5, working on the principle of the steam separator, is connected in series with the absorption chamber. In this separator the gas is forced to turn through an angle of 180 deg., while moving at a high velocity with the result that the heavier particles are thrown down, and collected in the bottom of the chamber.

From the separator, the gases pass to the precipitator, Fig. 5, in order that the finer particles of fog may be collected. This device is patterned after that of Cotrell. A glass tube, about $11 / 2$ inches $(3.81 \mathrm{~cm}$.$) in diameter and 23$ inches $(58.4 \mathrm{~cm}$.) in length, is coated with tinfoil up to within about six inches $(15.2 \mathrm{~cm}$.) of either end. The air passes in and out through the two side outlets blown in the glass near either end. A small (1/16-inch (1.59-mm.) diameter) aluminum wire, threaded throughout its entire length, is sealed into two small glass tubes about four inches $(10.2 \mathrm{~cm}$.) in length, which in turn are sealed into either end of the precipitator tube. Thus, quite a long creepage distance is secured, which is necessary when the surfaces become wet with nitric acid. This tube is operated with an induction coil giving a one-half inch $(1.27 \mathrm{~cm}$.) spark between needle points.

With the induction coil connected to the precipitator in such a way tha! the larger lobe of the wave is impressed on the threaded wire, the tube seems to work well. The smaller lobe is more or less excluded by point plate action.

Air Control. A small piston air pump is connected to a system of valves, in such a way that the discharge tube may be operated under pressures above or below the atmosphere, by a simple manipulation of the valves. The valves are provided with a pointer and dial, so that settings may be duplicated at any time. The fluctuations due to the pump are smoothed out by the use of an air tank, whether the system is working under pressure or vacuum. The air pump is driven by a d-c. motor, arranged with armature con- 
trol of the speed. A voltmeter is connected across the armature circuit to act as an indicator of the motor speed.

Air leaving the pump bubbles through sulphuric acid, contained in two chambers in series, and then passes on through a tube containing soda lime. By this process the air is rendered practically free from moisture and carbon dioxide.

A special gas meter, having a capacity of $100 \mathrm{cu} . \mathrm{ft}$.,

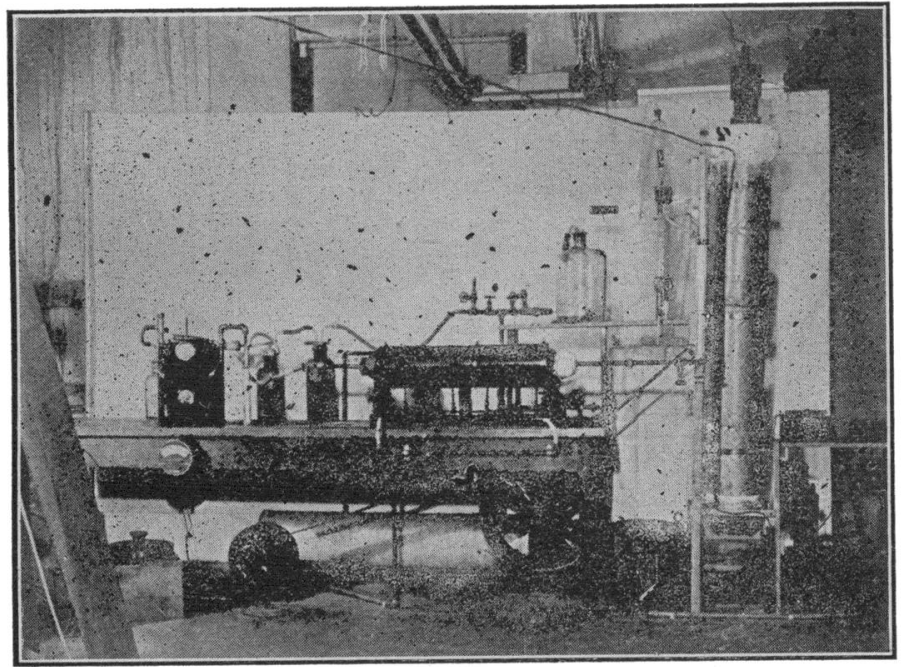

Fig. 6-Experimental Apparatus

(28.32 liters) is connected to a settling chamber through which the air passes after leaving the soda lime chamber. By use of the large dial with which the meter is provided, readings are possible to one one-hundredth (0.01) of a cu. ft. (0.283 liter). The temperature and pressure of the air at the air meter are measured because the air meter is not capable of withstanding all of the pressures used in the discharge tube.

Upon leaving the air meter, the air passes through an air heater, where its temperature may be raised as much as required. This heater consists of a long tube, heated by ten gas burners, properly insulated to prevent excessive radiation. In some of the earlier work, the heater was used in conjunction with the heating 
element on the discharge tube to hold a constant temperature. It was found however, after several trials, that small temperature changes did not seem to affect the yields materially, and as a result all of the tests recorded in this paper were made at room temperature.

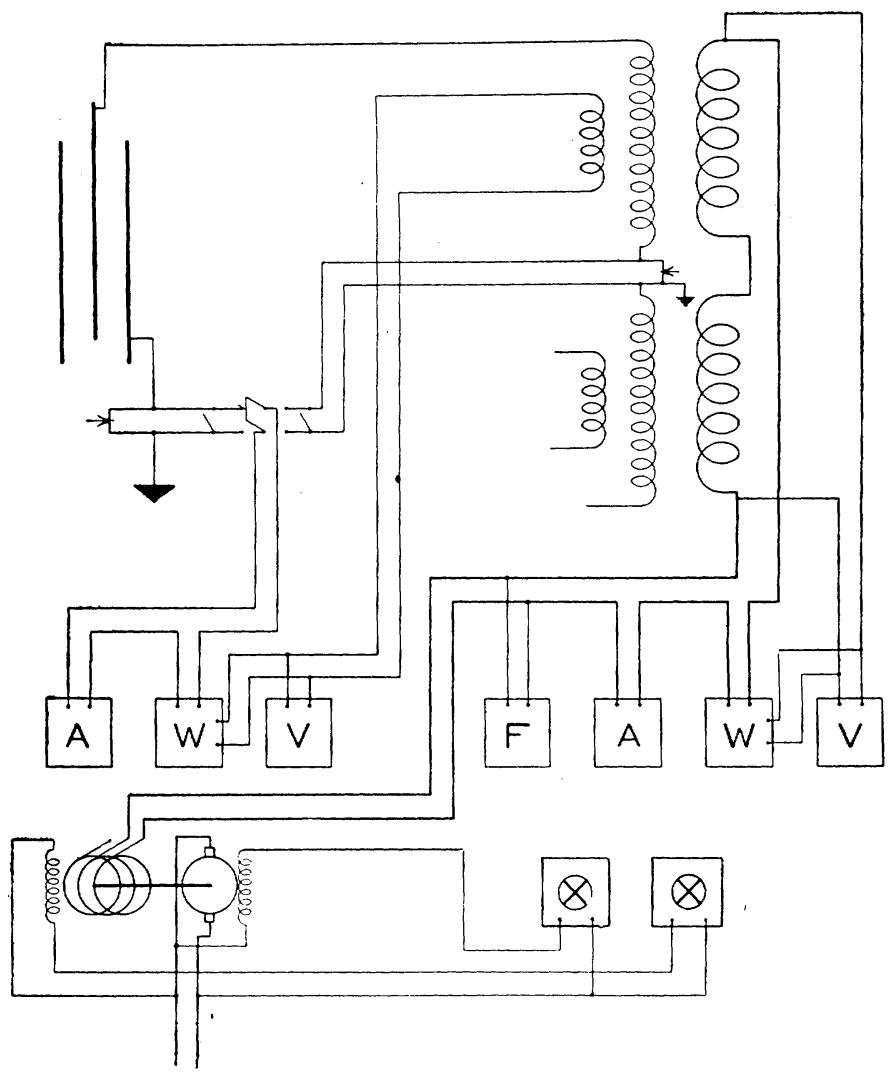

Fig. 7-Diagram of Connections

This was of course held as nearly constant as possible. It is planned to make a set of runs in which the temperature will be made the independent variable. Upon leaving the gas heater the air passes through a valve, used for regulating the tube pressure, and then enters the discharge tube.

Power Measurement. The high-tension winding of the transformer was grounded at its neutral point. The other terminals were connected to high-tension 
buses. Each half of the secondary may be operated up to $100 \mathrm{kv}$. The excitation for the transformer is furnished by an alternator which gives practically a sine wave.

A test table has been arranged, equipped with various meters and rheostats. On this table, switching ar-

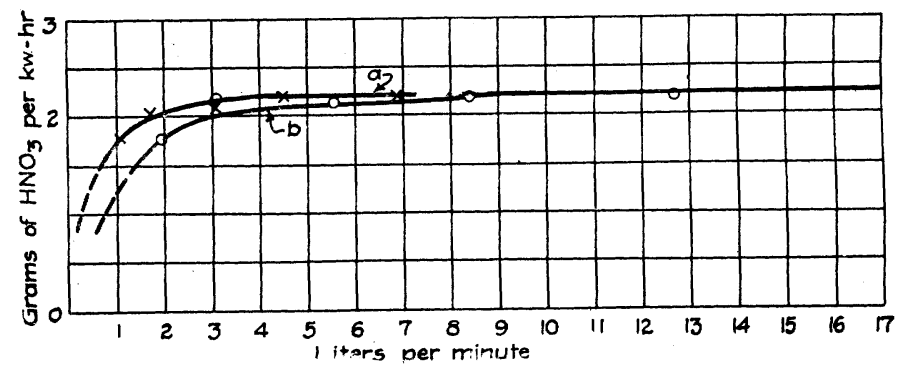

Fig. 8-460 мм.

a.-n.t.p.

b.-actual.

rangements, Fig. 7, are provided so that the current in either circuit, $i$. e. from transformer to ground or, from discharge tube to ground, may be read on the same milliammeter. These currents differ because of

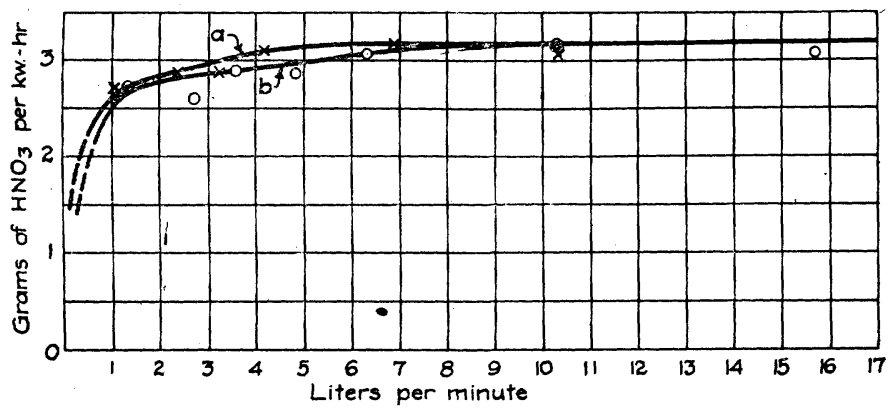

Fig. 9-560 мм.

a.-n.t.p.

b.- actual.

the capacity of the transformer coils to ground, and also because of the actual electrostatic leakage occurring in the transformer.

A special low-reading wattmeter, whose potential coil is connected to the tertiary coil on the transformer, has its current coil in series with the milliam- 
meter in order that readings of watts in tube circuit and transformer circuit may be taken independently. There is some considerable variation in the readings of the wattmeter in the two circuits with varying pressure in the discharge tube. This variation in wattmeter readings appears to be a function of the static

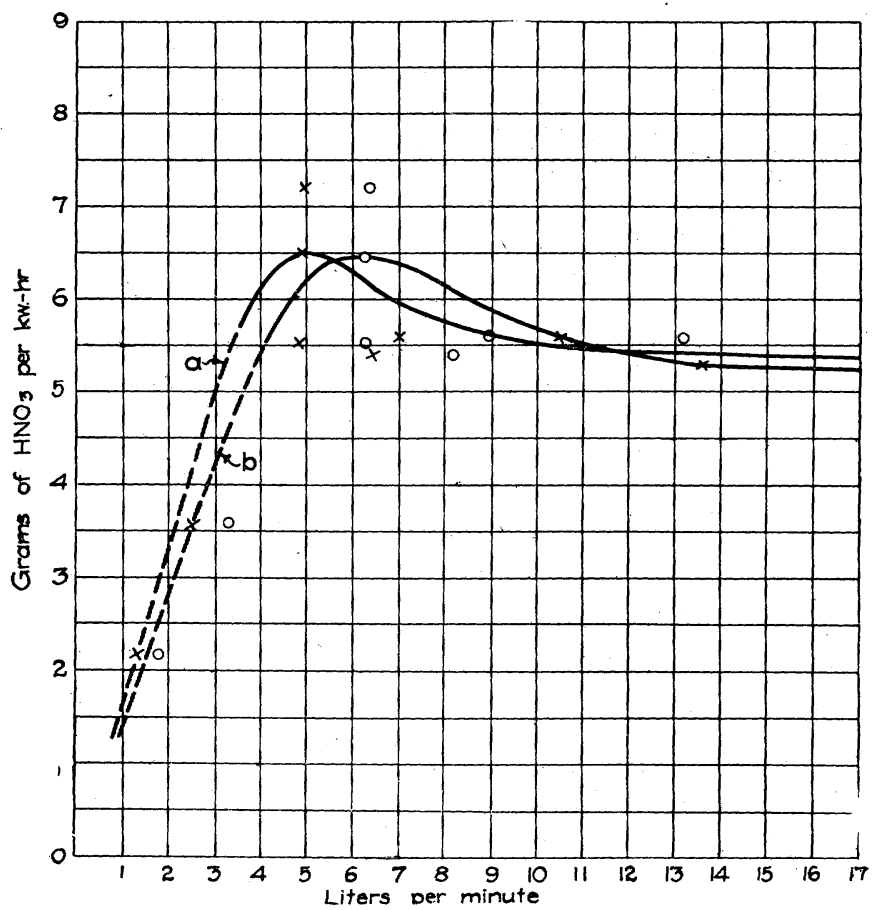

Fig. 10-660 мм.

a. -n.t.p.

b.-actual.

sparks in the tube, and is greater than can be accounted for by capacity effects alone. This matter will be the subject of future investigation.

Meters were connected in the primary circuit of the transformer for measuring the input power. The net power measured from the primary side has checked that observed on the secondary side within 10 per cent in practically every run made.

Results of Tests. A series of runs at pressures of $460,560,660,710$, and $780 \mathrm{~mm}$. has been made. The power in the transformer circuit to ground was held 
constant during all of these runs. The frequency was 60 cycles. Each run was 45 minutes in length. For each pressure a series of runs was made with air velocity as the variable. Figs. $8,9,10,11$, and 12 show the yield of $\mathrm{HNO}_{3}$ per kilowatt-hour of energy expended in the tube. The curves marked "actual velocity" refer to the actual velocity of a particle in passing through the discharge tube.

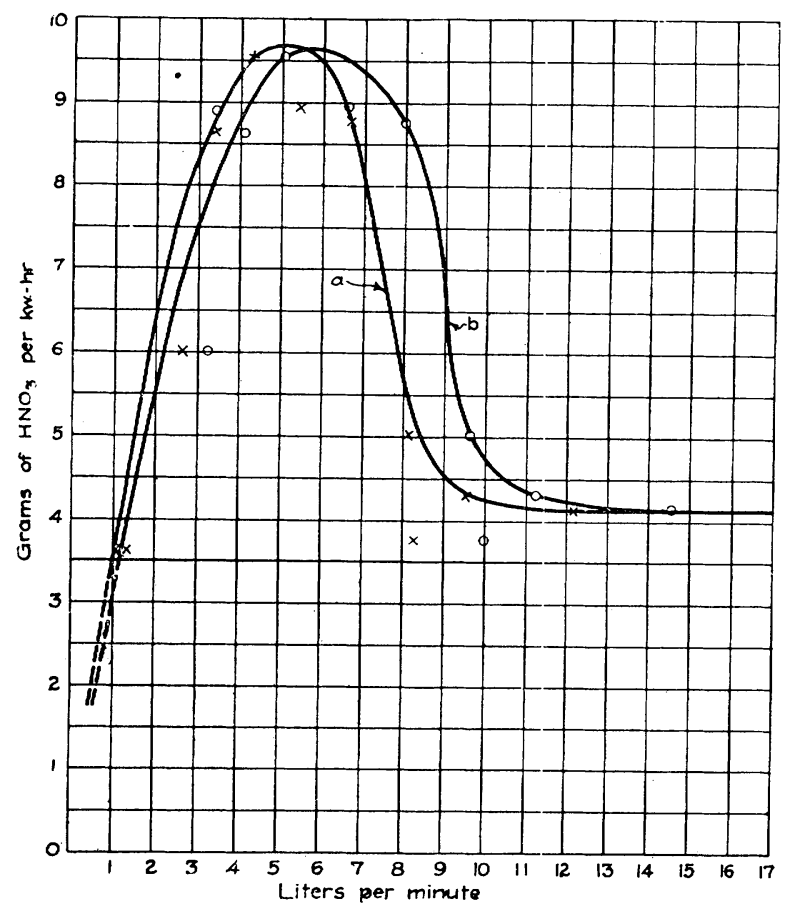

Fig. 11-710 мм.

a.-n.t. p. $\quad$ b. -actual.

Figs. 13 and 14 show the relation between pressure and yield with constant air velocity. From these curves it may be seen that the yield at the lower velocities is limited, but that at the higher velocities the limit has not yet been approached.

From the equations for the formation of nitric acid, it may be seen that the concentration of $\mathrm{N}_{2} \mathrm{O}_{5}$ will be half that of $N O$ for any given value of nitric acid. 
$2 \mathrm{NO}+\mathrm{O}_{3}=\mathrm{N}_{2} \mathrm{O}_{5}$

$\mathrm{N}_{2} \mathrm{O}_{5}+\mathrm{H}_{2} \mathrm{O}=2 \mathrm{H} \mathrm{N} \mathrm{O}_{3}$

The $\mathrm{N} \mathrm{O}$ first iormed is oxidized to $\mathrm{N}_{2} \mathrm{O}_{5}$ by the excess of ozone present so the $\mathrm{N}_{2} \mathrm{O}_{5}$ may be contrasted with $2 \mathrm{~N} \mathrm{O}$ for the same yield of nitric acid.

The relation between per cent thoncentration of fixed nitrogen, calculated as $\mathrm{N} \mathrm{O}$, velocity and pressure

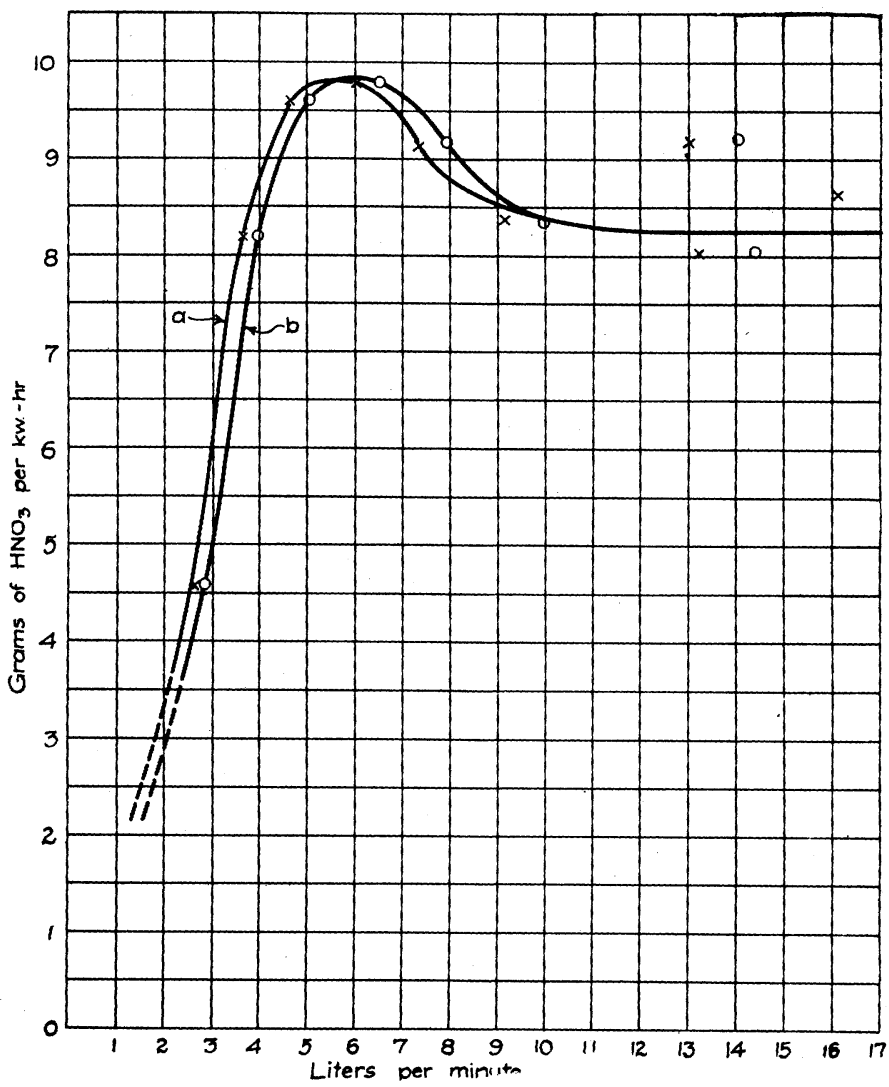

FIG. 12-780 мм.

a.-n.t. p.

b.-actual.

is given in Figs. 15 and 16. These curves show that high concentration is to be secured at low velocity, but as seen in Figs. 13 and 14 at the expense of energy input. The concentration curves are therefore somewhat misleading from a commercial standpoint.

It seems probable that all of the velocity-yield runs 


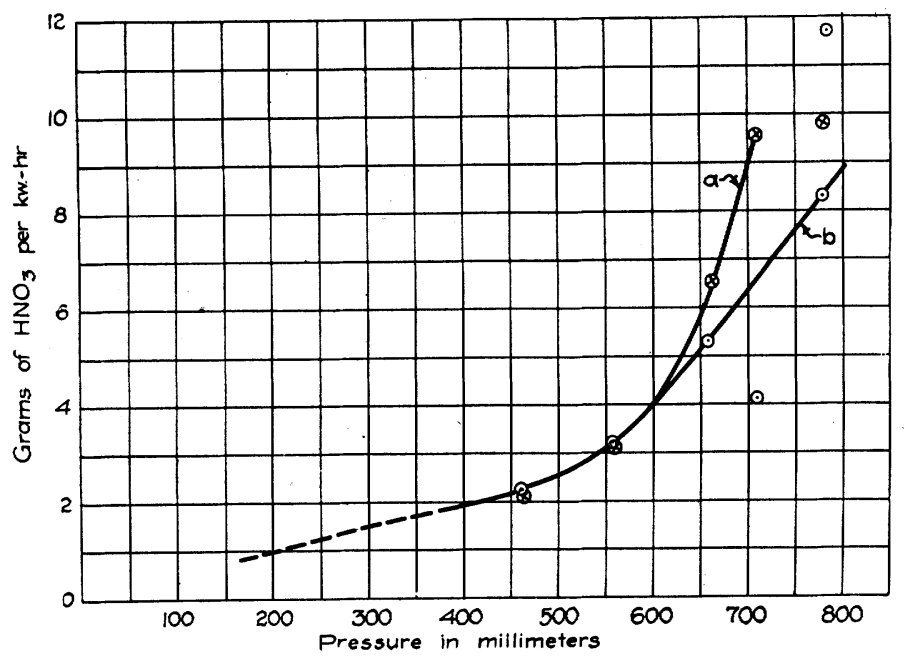

Fig. 13-Pressure Yield Curves Constant Air Velocity (n.t. p.).

for the different pressures should follow the same general form. At low pressures the amount of gas to be dissolved was low and the efficiency of absorption higher. At the higher pressures, with more gas to take up, it is likely that the absorption was incomplete,

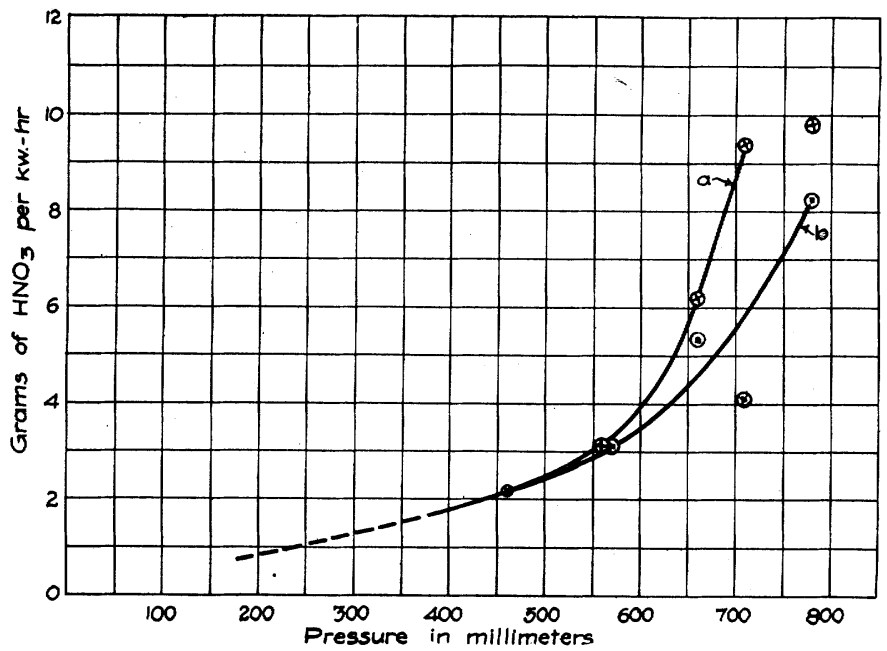

Fig. 14-Pressure Yield Curves

Constant Aír Velocity (actual). 
especially at high velocities. Data taken recently have shown this to be the true condition.

From Fig. 12 the highest yield is seen to be 9.8 grams $\mathrm{H} \mathrm{N} \mathrm{O}_{3}$ per kilowatt-hour. This is more than double the average yield obtained with the original apparatus. (Table I). From the results of unfinished work it is apparent that this yield can be materially increased by using the improved methods of absorption which are now being worked out. The $\mathrm{NO}$

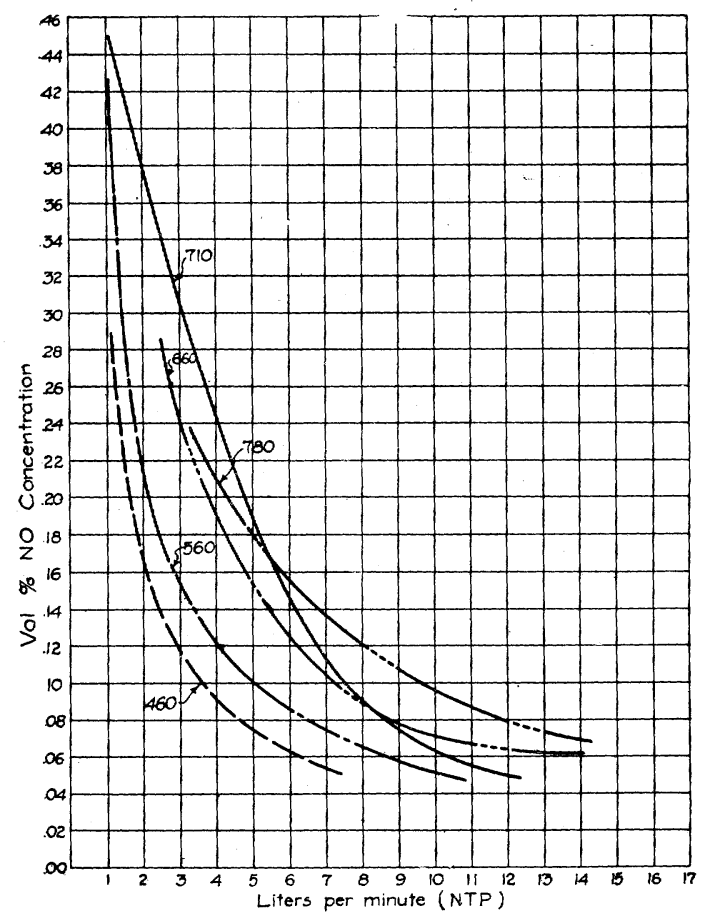

Fig. 15

concentration for this velocity and pressure is 0.204 per cent.

One of the greatest complications of this problem is the number of variables to be controlled. The large number of variables explains the apparent contradictions so often found in the literature of the silent discharge. It has taken considerable time and patience to acquire the ability to secure sufficiently 
constant conditions so that runs may be made which will check satisfactorily. Very great care has been necessary in making the various runs and taking the data, to eliminate as far as possible personal errors.

Considerable difficulty encountered in the early work was that of keeping the joints tight. The situation was complicated by the fact that rubber

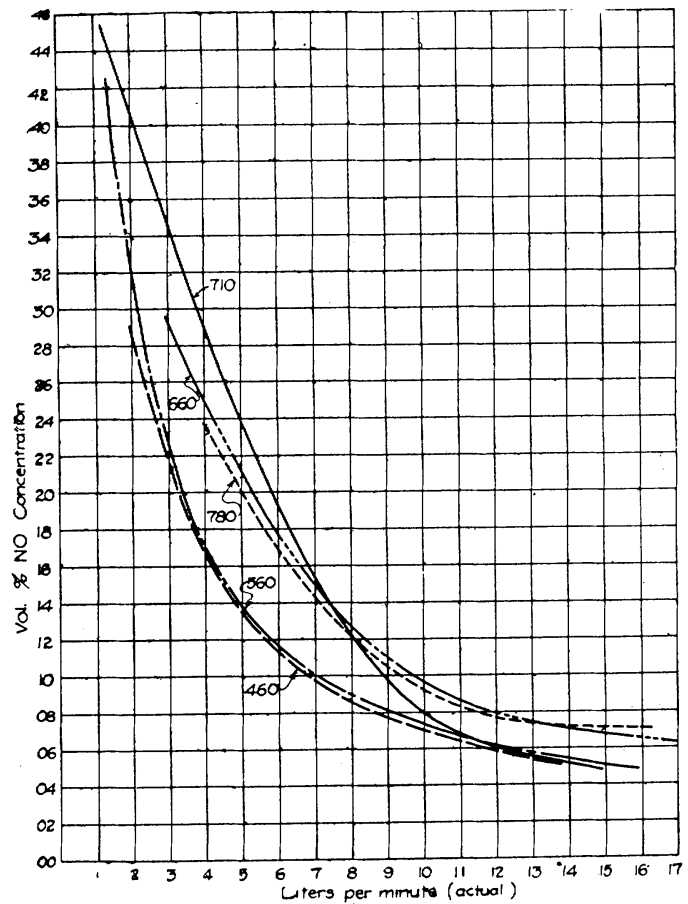

FIg. 16

joints in contact with ozone are destroyed in a very few minutes.

A beeswax, sealing wax, and rosin compound, which has been referred to before, was developed for use in making joints and has given excellent results. The proportions by weight are: Sealing wax 3 ; beeswax 2 ; rosin 5. The joints are made in about the same manner as the plumber wipes a lead joint.

Incidental Phenomena.-Fog. At certain air pressures and velocities a white fog is formed over the sur- 
face of the absorption liquid. In the low pressure tests slight fog is formed, while at the higher velocities no fog appears. In many cases the fog is an initial condition disappearing after the first ten or fifteen minutes of operation. As the pressure is increased the fog becomes stronger and in general remains longer, until at $780 \mathrm{~mm}$. pressure the fog, at a velocity of six liters per minute, is so dense that it is not possible to see through three inches of it. The fog is found to contain some nitric acid, its concentration being subject to considerable variation. The fog formation is being investigated further.

Meter and Pressure Variation.-At certain air velocities the readings of all the meters connected in the transformer and tube circuits and, to a lesser degree those in the primary circuit show a cyclic variation. At low pressures the effect is very slight, but with increasing pressure it becomes more pronounced. The greatest variation at each pressure occurs at an actual velocity of six liters per minute. At velocities above and below this, the indications rapidly become steady. With but one exception, these variations do not extend over a period of more than 40 minutes. In most cases they do not occur after the first 20 minutes of operation.

When the variations are most pronounced, the manometer connected to the discharge tube shows a disturbance corresponding to that of the electric meters. The frequency seems to be about two per second, although it is not by any means constant.

From the velocity yield curves given in Figs. 8, 9, 10,11 , and 12 , it is to be noticed that the curves begin to flatten out at about the critical velocity of six liters per minute.

In the discharge tube, nitrogen pentoxide $\left(\mathrm{N}_{2} \mathrm{O}_{5}\right)$ is being formed, while at the same time, if subjected to discharge for too long a period, it is again broken down. These two actions are therefore opposing one another and both are a function of time. This action may have some bearing on the observed variations.

Another effect which should be mentioned has been termed "Initial effect." During practically every run 
made, in order to hold the wattmeter deflection constant, the primary voltage had to be reduced as the run progressed. This average potential decrease during runs amounted to about 3 per cent. The tertiary coil voltage did not show as high a percentage variation and in some cases no change was noted. Most of the observed changes took place in the first fifteen minutes of operation.

Analysis of Losses. The energy consumption in the discharge tube may be divided into four parts.

1. Warming up the Material of the Tube. Using the weight of the iron and aluminum parts of the tube, and the specific heats of the metals, an expenditure of 14.14 watthours will be required per degree cent. temperature rise.

2. Loss in the Porcelain Dielectric. In order that some idea of the magnitude of the dielectric losses in the porcelain might be obtained, a series of heat runs on a regular discharge porcelain tube was made. The outside of the tube up to within about a foot $(30.5 \mathrm{~cm}$.) of either end was covered with tinfoil, the corona discharge from the tinfoil edges being prevented by pressboard collars sealed over them. A snug fitting metal tube three inches $(7.6 \mathrm{~cm}$.) in diameter was slipped inside the porcelain, its length being such that the dielectric field was not distorted by its ends. The tinfoil was grounded, the inner tube being connected to the high-tension supply. Alcohol thermometers placed on the tube indicated the temperature of the tube. From curves taken during this test the power loss in the porcelain dielectric will be of the order of 10 watts, its exact value depending upon the value of the current flowing, in any particular case. From the observed temperatures of the discharge tube and effluent gases the temperature rise of the porcelain is greater than that which would be caused by its own dielectric loss. On account of this the energy calculated as being used in warming up the porcelain will exceed the value obtained by test.

3. Heat Carried away by Discharge Gases. The amount of heat carried away by the air is very small, 
being of the order of 0.20 watthour per 1000 liters of air per degree cent.

4. Energy used in the Chemical Reactions. Using the figures given by Berthelot the amount of energy required for the formation of enough $\mathrm{N}_{2} \mathrm{O}_{5}$ to produce one gram of nitric acid is 95.4 calories, or 0.11 watthour. For the ozone 667 calories or 0.78 watthours are required.

Assuming that the wrought iron tube and the aluminum tube are at the same temperature, and that the porcelain tube is at the temperature of the discharge gases the following energy relations are secured, based upon their respective weights, specific heats and assumed temperatures.

Metal parts average rise 5.6 deg. cent. loss $=79.2$ watthours Porcelain tube average rise $9.35 \mathrm{deg}$. cent. loss

Effluent gases $9.35 \mathrm{deg}$. rise-478 liters loss Chemical reactions 2.13 grams $\mathrm{H} \mathrm{N} \mathrm{O}_{3}$

(per hour) $\ldots \ldots \ldots \ldots \ldots \ldots \ldots$

0.96 grams ozone

$=27.1$ watthours

$=0.9$ watthour

$=0.24$ watthour

$=0.78$ watthour

108.2

The power read on the wattmeter when connected in the tube circuit was 134 watts, leaving a difference of 25.8 watthours to be accounted for. Some of this may be due to temperatures existing inside the discharge tube higher than those used in the calculations. This error is not likely to be very large, however.

Conclusions. This work is but well begun, and no prediction can be made with any degree of certainty, yet the results obtained thus far are quite promising. Improved absorption apparatus has already indicated that increased yields may be expected. The process is very simple, and the first cost and maintenance of a plant would not be high. The difficulties of operation associated with the use of high temperatures are obviated.

Referring to Anderegg's calculations, ${ }^{5}$ based upon his

4. Smithsonian Physical Tables, 6th Edition.

5. "The Calculation of the Efficiency of the Silent Discharge Process for Nitrogen Fixation," F. O. Anderegg, Science, 50, 49 (1919) and Chemical Abstracts 13, 3090 (1919). 
theory of the reaction, the ideal yield from the silent discharge process, if all the electrical energy were available for the reaction, would be 250 grams of nitric acid per kilowatt-hour. The theoretical possibilities from the thermal reaction, according to thermodynamical calculations, represent a yield of only 134 grams of acid per kilowatt-hour at a temperature of 4200 deg. cent. If the former process can be developed to the present efficiency of the arc process, the yield will be greater and the first cost and operating expenses will probably be much less because of the simpler apparatus involved.

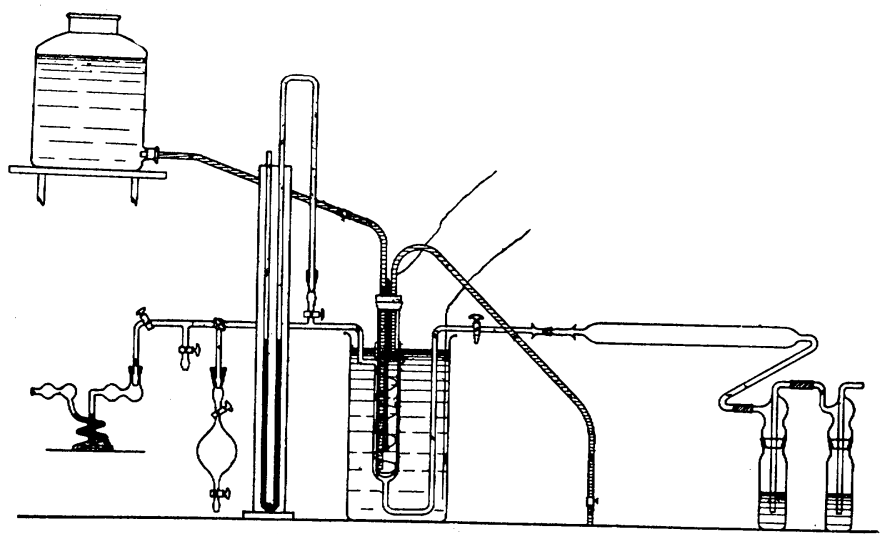

Fig. 17-Spiel's Apparatus

In general, those reactions approximating most closely natural phenomena are found ultimately to be most satisfactory and economical. Nature provides dilute nitric acid for the fertilization of the soil by the ionization of the air as a result of electric discharges in the atmosphere. The gases thus produced are absorbed by the moisture of the clouds or rain and are distributed over the land. Such a process is identical in principle with that under discussion in this paper.

This work has been accomplished only by the generous cooperation of many interested investigators. Dr. F. O. Anderegg in particular, Assistant Professor of Chemistry at Purdue University, has followed the work in detail and has made many suggestions of value. The hearty appreciation of the authors is ex- 
tended to him, to other collaborators mentioned in the paper, to Professor H. C. Peffer, Head of the School of Chemical Engineering, and Mr. Emerson Pugh, instructor in the School of Electrical Engineering. The departments of Chemistry and Physics have also rendered services which are hereby recognized with appreciation.

The Engineering Experiment Station at Purdue University will continue the investigation of the "Fixation of Atmospheric Nitrogen by the Silent Discharge Process."

\section{APPENDIX}

In Table I will be found a summary of the results of Spiel's experiments upon fixed volumes of air. The change of primary current of the induction coil indicated in the second column of the table, no doubt varied the voltage of the secondary and therefore the energy input to the Siemen's tube over a considerable range, but no record of such energy or the yields of nitric acid were reported.

TABLE I.

SUMMARY OF SPIEL'S RESULTS

\begin{tabular}{|c|c|c|c|c|c|c|}
\hline $\begin{array}{l}\text { No. of } \\
\text { exper- } \\
\text { iment. }\end{array}$ & $\begin{array}{l}\text { Prim. } \\
\text { cur- } \\
\text { rent. }\end{array}$ & $\begin{array}{c}\text { Pressure } \\
\text { mm. }\end{array}$ & $\begin{array}{l}\text { Tempera- } \\
\text { ture } \\
\text { deg. cent. }\end{array}$ & $\begin{array}{l}\text { Time } \\
\text { reversal } \\
\text { minutes }\end{array}$ & $\begin{array}{l}\text { Time } \\
\text { equili- } \\
\text { brium } \\
\text { minutes }\end{array}$ & $\begin{array}{c}\text { N O } \\
\text { concen- } \\
\text { tration } \\
\text { vol. } \\
\text { per cent }\end{array}$ \\
\hline 1 & 1.9 & $715 \quad-744$ & $12-15.3$ & 120 & 175 & 0.7 \\
\hline 2 & 1.9 & $\begin{array}{ll}716 & -748.5\end{array}$ & $14-14.2$ & 110 & . & 4.4 \\
\hline 3 & 1.9 & $481.5-503.5$ & 14.3 & 39 & 51 & 0.6 \\
\hline 4 & 1.9 & $481.5-502$ & 15 & 43 & $\ldots$ & 5.6 \\
\hline 5 & 1.9 & $345.5-353.5$ & $16-16.1$ & 14 & 85 & 0.5 \\
\hline 6 & 1.9 & $344 \quad-352$ & $15.5-15.7$ & 11 & $\ldots$ & 6.6 \\
\hline 7 & 3.0 & $729.5-746$ & $\begin{array}{ll}17 & -17.1\end{array}$ & 30 & 50 & 0.4 \\
\hline 8 & 3.0 & $721.5-746.5$ & $16.1-16.2$ & 31 & $\ldots$ & 4.2 \\
\hline 9 & 5.0 & $731-760$ & $14-14.2$ & 11 & 80 & 0.1 \\
\hline 10 & 5.0 & -750 & 14 & 11.5 & $\cdots$ & 3.6 \\
\hline
\end{tabular}

The analyses were made after the equilibrium was reached for the experiments of odd number. In the even numbered experiments, the analyses were made as near the reversal point as possible.

\section{CONCLUSIONS}

The conclusions derived by Spiel as the result of his work on air are quoted as follows: 
1. "With the discharge in enclosed volumes of air the final equilibrium concentration gives nitric oxide below one volume per cent for these conditions."

2. "Decrease of the original pressure essentially alters the equilibrium concentration."

3. "Increase in the primary current decreases the equilibrium concentration."

4. "The pressure decrease, which the gas undergoes, as is to be seen from curve, Fig. 17, varies between 8 and $34 \mathrm{~mm}$. This pressure decrease depends not only upon the formation of ozone, but also upon the formation of oxides of nitrogen for, as can be seen

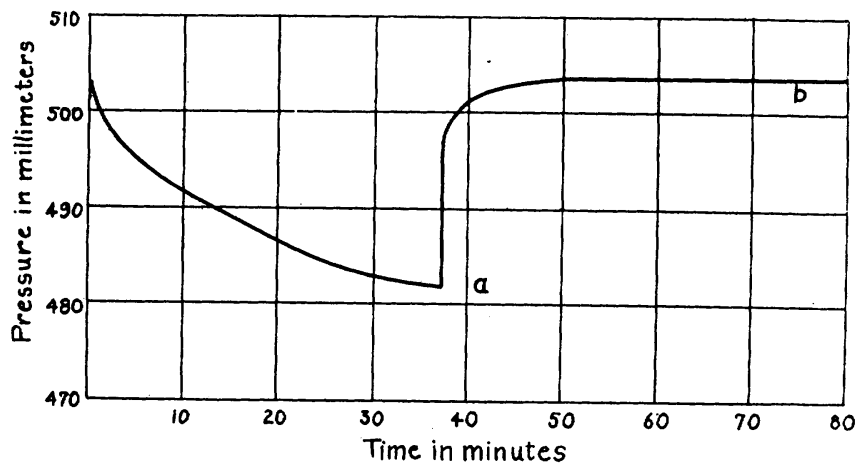

FIG. 18

a. -5.6 vol. per cent $\mathrm{NO}$.

b. -0.6 vol. per cent $\mathrm{N} O$.

from the red color of the gas at the time of reversal, and as has been proven by the determinations of concentration, much more oxidized nitrogen is present before and at the time of reversal, than at equilibrium."

This abrupt and strong reversal is a very peculiar phenomenon. It has been checked by Anderegg in the chemical laboratory of Purdue University. The reversal has been shown by Spiel to be affected by changes of temperature. An investigation is being undertaken by R. E. Nelson to see what effect the maintenance of a very constant temperature will have on the reversal.

5. "The concentration at the time of reversal in experiments at atmospheric pressure is about six 
times the final concentration. For lower pressures this ratio is raised, the final concentration being lowered; the reversal concentration increases rapidly. With $500 \mathrm{~mm}$. pressure at the time of reversal about 10 times, with $350 \mathrm{~mm}$. about 12 times as much NO is present as in the final equilibrium."

6. "With increased current the reversal as well as the final concentration decreases considerably."

7. "The time after which reversal occurs varies between 12 and 110 minutes; the latter time, which was obtained with air at atmospheric pressure and 1.9 amperes, agrees with the results of HantefeuilleChappius."6

The conclusions reached by Spiel resulting from experiments with initial mixtures of air and various proportions of oxygen and nitrogen are to the effect that the concentration is increased and the time required to produce a reversal of the reaction is lowered by higher oxygen concentrations. He further decides the "The Silent Electric Discharge is not concerned with a thermal effect."

6. Comptes rendus 92 (80), 1881; 92 (134), 1882. 
Discussion ON "Nitrogen FIXATION BY THE SILENT DischaRge METHOD" (HARDING AND McEachron), Boston, Mass., APRIL 9, 1920.

Mr. Finch: I should like to ask Mr. Harding if he made any runs at a higher pressure, say 2 or 3 atmospheres, at the same time increasing the velocity?

Mr. Benjamin: I might state that in the demand for argon for filling electric light bulbs in 1916, I was called upon by my company to develop a method for the obtaining of argon. In connection with that I naturally turned to the Berklinite process to remove the nitrogen from the air and eventually developed an apparatus which is extremely simple, being a reaction chamber provided with 4 electrodes. These electrodes were nickel. Two diametrically opposite electrodes were arranged to receive a discharge current from an a-c. transformer; it was only a 5 -kw. transformer giving a secondary voltage of 30,000 volts. This sets up a spark. Another two diametrically opposite electrodes were placed fairly close so that their axes were at right angles to their high potential electrodes, and these received a 30 -volt d-c. current. The circuit could not be established until the a-c. arc was formed; in the reaction chamber at the top, we arranged a spray which sprayed the interior of the walls of the reacting chamber with sodium hydroxide which was fed in. The gases consisted of air and oxygen. We found a very peculiar condition. Theoretically we take it that 8 parts of air and 9 parts of oxygen would form a complete reaction, but we had very poor results, practically no results, until we supplied a surplus of oxygen, amounting to 11 parts of oxygen to 8 parts of air, and then the reaction became violent, the entire reaction chamber was filled with a yellow glow which you could not detect as caused by the d-c. arc or the a-c. arc, being a natural sodium flame effect. Our products were completely converted by circulating sodium hydroxide until the gases were completely consumed and formed sodium nitrate, the residual gas being the rarer elements of the air, such as argon, helium. The other remaining gases we did not attempt to analyze. This process was extremely simple, as it consisted of just one reaction chamber and air circulating system for the sodium hydroxide.

K. B. McEachron: The results, as you can see from the curves, indicate that the higher pressures and higher velocities give the bestyields. We havenot done any work at any higher pressures than those reported in the paper. In case the pressure was increased materially the voltage would also need to be increased to produce a 
satisfactory corona. For several reasons this is not feasible with the present design of tube, one of the most important limitations being that the creepage distance at the top of the tube is such that the voltage cannot be increased very materially without danger of flashing over.

We have considered the advisability of introducing certain absorbing liquids, as sodium hydroxide or water vapor, into the discharge chamber. We have found however that dry air is very much better than moist air, and all of the air we use has been dried. The trouble with moist air is that sparksform very readily which seem to hinder the reaction. If the air contains much moisture, a portion of the yield of nitric acid will adhere to the walls of the discharge chamber, thus diminishing the observed yield. The presence of nitric acid inside the discharge tube is also likely to cause a short circuit at the bottom of the tube, where the surface of the insulating materials becomes more or less conducting.

Mr. Tucker: The authors refer to a higher yield than that indicated in the paper; could they give us any figures on that?

K. B. McEachron: We are not quite ready to give any definite values for the increased yields referred to. I might say, however, that we have obtained yields more than twice those mentioned in the paper. The reason why we do not want to give this information is on account of the possible error in our power measurements. To measure 100 or 200 watts with an electric potential of 50,000 or 60,000 volts is a problem which offers considerable difficulty. Until we have more definite information regarding our power measurements, we do not wish to put these data on record. We hope to obtain a check on our measurements by the oscillographic method, which method we are using now.

Mr. Benjamin: I might state that I have experienced trouble with porcelain insulation in that respect and have resorted to lava, I believe made somewhere about Chattanooga, that gave perfect results and no crazing on the surface whatever such as we have experienced with porcelain, and gave perfect electrical insulation.

K. B. McEachron: The process described in the paper should prove to be a valuable one, if the yields can be made to equal or exceed those of the arc process. A large amount of work will necessarily have to be done in order that the conditions which produce the best yield may be determined. When new data of sufficient value has been obtained, further reports will be made to the Institute. 